\begin{tabular}{lll}
\hline AECORDS OF PHARMACEUTICAL \\
AND BIOMEDICAL SCIENCES
\end{tabular}

\title{
Review article on Nanoemulsions and Nanostructured lipid carriers
}

\author{
Samar H. Faheim * ${ }^{(a)}$, Ahmed R. Gardouh ${ }^{(b)}$, Ahmed T. Nouh ${ }^{(\mathrm{c})}$, Mamdouh M. Ghorab ${ }^{(\mathrm{b})}$ \\ ${ }^{a}$ Department of Pharmaceutics, faculty of pharmacy, Horus University, New Damietta, Egypt,${ }^{b}$ Department of \\ Pharmaceutics and Industrial Pharmacy, faculty of pharmacy, Suez Canal University, Ismailia, Egypt, ${ }^{c}$ Department of \\ Pharmaceutics, faculty of pharmacy, Delta University, Gamasa, Mansoura, Egypt.
}

\section{Received on: 8.9. 2018}

Revised on: 4. 10. 2018

Accepted on: 10.11. 2018

*Correspondence Author:

Business Tel:

$+01010763817$

E-mail address:

dr.samar.hamed@gmail.com

\begin{abstract}
Lipid nanoparticles, including nanoemulsions (NEs) and nanostructured lipid carriers (NLCs) are colloidal carriers with a lipid matrix that is solid at body temperature. These colloidal carriers have attracted increasing interest for their use in therapeutic and cosmetic applications. The performance of lipid nanoparticle formulations is greatly influenced by their composition and structure. Lipid nanoparticles are generally composed of lipids, surfactants and co-surfactants. The lipid materials used in the production of lipid nanoparticles are usually solid at room temperature. Being well-tolerated in physiological conditions, lipid nanoparticles are typically biocompatible. Liquid lipids, or oils, are specifically used for production of NLCs. In most cases, lipid nanoparticles are produced as dispersions and surface-tailored with surfactants to improve dispersion stability. It was shown that NLCs reveal some advantages for drug therapy over conventional carriers, including increased solubility, the ability to enhance storage stability, improved permeability and bioavailability, reduced adverse effect, prolonged half-life, and tissue-targeted delivery.
\end{abstract}

Keywords: Nanotechnology, nanoemulsion, nanostructured lipid carrier

\section{Introduction}

Nanotechnology provides many benefits to drug delivery systems. new systems have been extensively studied to enhance the efficacy of therapeutic agents such as liposomes, micelles, dendrimers, and metal colloidal (diameters less than $100 \mathrm{~nm}$ ) (Agarwal et al., 2008; Cho et al., 2008; Kaur et al., 2008; Parveen and Sahoo, 2008; Tallury et al., 2008). Because of their small size and excellent biocompatibility, nano-sized drug carriers have a small size and excellent biocompatibility, which enable them to circulate in the bloodstream for a long period of time, reach the target site, effectively deliver therapeutic agents and all the while minimizing the inefficiency and side effects of free drugs. The latest advances in nanotechnologies, especially in nanoparticles, make them more favorable in drug discovery, delivery of therapeutics, and diagnostics (Yang et al., 2006). The nanoparticles (NPs) have many advantages as drug delivery systems such as targeting the drugs to specific sites of action, organ or tissues, delivery of biological molecules such as proteins, peptides, and oligonucleotides, and protection of drugs against degradation. many applications of drug nanoparticles have been studied such as systemic drug delivery of biodegradable nanoparticles and drug dissolution modification of non-biodegradable nanoparticles (Brannon-Peppas, 
(Brannon-Peppas, 1995; Couvreur et al., 1995; Schmidt and Bodmeier, 1999; Soppimath et al., 2001). Advanced applications for drug nanoparticles vary from drug targeting and delivery (Brigger et al., 2012; Chawla and Amiji, 2002; Couvreur et al., 1995; Labhasetwar et al., 1997; Soppimath et al., 2001; Vauthier et al., 2003; Yang and Alexandridis, 2000) to even gene(Cohen et al., 2000; Lambert et al., 2001; Panyam and Labhasetwar, 2003) and protein therapies (Damge et al., 1990; Damge et al., 1997). Administration of nanoparticles by different routes, for example, parenteral (Brannon-Peppas, 1995) ocular (Gurny et al., 1985; Khopade and Jain, 1995; Pignatello et al., 2002), transdermal (De Vringer and De Ronde, 1995), and oral routes have been studied. Nonetheless, the oral route is still the most appropriate, preferred, and in many cases, also the most inexpensive method of drug administration (Barratt, 2000; Damge et al., 1990; De Jaeghere et al., 2001; Kreuter, 1991; Müller et al., 2001; Shekunov and York, 2000).

Nanoparticles have three main basic properties make them more favorable for drug delivery applications, these properties are:

1- Their small particle size which allows them to penetrate through smaller capillaries, so ensure efficient drug accumulation at the target sites (Panyam et al., 2002a; Sahoo et al., 2004).

2- Nanoparticle preparation makes use of biodegradable materials can allow sustained drug release within the target site over a period of days or even weeks (Panyam and Labhasetwar, 2004; Panyam et al., 2002b; Prabha and Labhasetwar, 2004).

3-Modification of the nanoparticle surface to alter the biodistribution of drugs or can be conjugated to a ligand to achieve target-specific drug delivery (Moghimi et al., 2001; Moghimi and Hunter, 2001).

\section{The advantages of using nanoparticles as drug delivery system include:}

- Stable dosage forms of drugs which are either unstable (Alai and Lin, 2015; Bhadra et al., 2016) or have unacceptably low bioavailability in nonnanoparticulate dosage forms (Madgulkar et al., 2016; Ramalingam and Ko, 2016). (2) they control and sustain release of the drug during the transportation and at the site of localization (Behera and Sahoo, 2012), altering organ distribution of the drug and subsequent clearance of the drug so as to achieve increase in drug therapeutic efficacy and reduction in side effects (Kadam et al., 2012).

- Site-specific targeting can be achieved by attaching targeting ligands to surface of particles or use of magnetic guidance (Lungu et al., 2016; Mohanraj and Chen, 2006).

- Controlled release and particle degradation characteristics can be readily modulated by the choice of matrix constituents. Due to biodegradability, $\mathrm{pH}$, ion and/or temperature sensibility of materials they allow sustained drug release within the target site over a period of days or weeks (Jung et al., 2000; Sahoo and Labhasetwar, 2003).

- They can pass through smallest capillary vessels and be taken up by cells, which allow efficient drug accumulation at the target sites (Desai et al., 1996; Desai et al., 1997; Panyam et al., 2003) because of their ultra-tiny volume and avoiding rapid clearance by phagocytes so their duration in bloodstream is greatly prolonged. This is especially needed for tumors which are characterized by extensive angiogenesis, defective vascular architecture, impaired lymphatic drainage and increased production of permeability factors. This phenomenon is known as the enhanced permeability and retention effect (Jung et al., 2000; Maeda et al., 2000; Yang et al., 2006).

- Increased active agent surface area results in a faster dissolution of the active agent in an aqueous environment, such as the human body. Faster dissolution generally equates with greater bioavailability, smaller drug doses, less toxicity (DUGGAL, 2011).

- Can be used for various routes of administration, including oral, nasal, intra-ocular and surface characteristics can be easily manipulated to achieve both passive and active drug targeting after parenteral administration

\section{- Reduction in fed/fasted variability}

- Due to the grand bioavailability, better encapsulation, control release, and less toxic properties, various nanoparticle systems with biodegradable polymers such as PLGA, PLA, chitosan, and gelatin are utilized for delivery of drugs of various types of diseases with better 
efficacy (Kumari et al., 2010).

- In recent years oral bioavailability of many of poorly water-soluble drugs can be improved by incorporating drugs into $\mathrm{pH}$-sensitive nanoparticles.

- Nanoparticles are now used to study the expression of therapeutic genes, is a useful tool for gene therapy.

- Pharmaceutical nano-carriers, that are designated as nanoparticulate drug delivery systems (NPDDS), can be classified in different ways, which are according to the raw materials, physicochemical characteristics (size, charge, number of lamellae, permeability), preparation methods, in vivo behavior. In a classification according to the materials used in their preparation, NPDDS can be of lipidic nature as liposomes, micelles, Transfersomes, and solid lipid nanoparticles, or of polymeric nature as nanoparticles, micelles, and niosomes (Couvreur and Vauthier, 2006; Crommelin et al., 2003; Torchilin, 2012).

- Different materials can be used to prepare nanoparticles such as proteins, polysaccharides, and synthetic polymers. The selection of matrix materials is dependent on several factors, including (a) the required nanoparticles size; (b) characteristic properties of the drug, e.g., aqueous solubility and stability; (c) surface characteristics such as charge and permeability; (d) degree of biodegradability, biocompatibility and toxicity; (e) required drug release profile; and (f) Antigenicity of the final product.

\section{Nanoemulsions (NEs)}

NEs are medication delivery systems comprising of emulsified oil and water systems with mean droplet diameters ranging from 50 to $1000 \mathrm{~nm}$. Generally, the normal droplet size is somewhere around 100 and $500 \mathrm{~nm}$ and can exist as oil-inwater $(\mathrm{o} / \mathrm{w})$ or water-in-oil (w/o) form, where the internal phase is either oil or water, separately.

\section{Composition of nanoemulsion}

NEs are formulated easily and sometimes spontaneously, generally without high-energy input. In many cases, a combination of a surfactant and cosurfactant are used with the oil and the water phases.
Depending on the composition of the NEs, Three types (Mishra et al., 2014) are most likely to be formed:

- Oil in water NEs where the oil droplets are dispersed in the continuous aqueous phase

- Water in oil NEs where the water droplets are dispersed in the continuous oil phase

- Bi-continuous NEs where the microdomains of oil and water are inter-dispersed within the system.

In all the types of NEs, the interface is stabilized by an appropriate combination of surfactants and cosurfactants. The ability of NEs to dissolve a large amount of low soluble medications alongside their common capacity to shield the medications from hydrolysis and enzymatic break down make them perfect medication conveyance vectors (Thiagarajan, 2011). These systems have points of interest for medication conveyance, for example, the utilization of physiologically tolerated lipids, largescale production, prevent the medications from destruction, enhanced bioavailability, controlledrelease qualities (MuÈller et al., 2000), Increase the rate of absorption, Provide aqueous dosage form for water-insoluble drugs, Various routes can be used to deliver the drug like topical, oral and intravenous, Rapid and efficient penetration of the drug, Helpful in masking the taste and require Less amount of energy (Mishra et al., 2014).

\section{Potential problems associated with NEs}

The flaws of NEs are poor drug loading capacities, medication deterioration during storage (Yuan et al., 2007), the use of large amount of surfactant and cosurfactant, NEs stability is influenced by environmental parameters such as temperature and $\mathrm{pH}$. These parameters may change when delivery to patients (Alvarez-Figueroa and Blanco-Mendez, 2001). In addition, a reason preventing a wide presentation of lipid emulsions (LEs) is that they have physical instability that can be increased by the joined drug (Teeranachaideekul et al., 2007). The flaws of NEs are overcome or minimized by the development of a novel type nanoparticle called Nanostructured lipid carriers (NLCs).

\section{6- Nanostructured lipid carriers (NLCs)}

NLCs made out of a strong lipid network with a sure substance of a fluid lipid are another era of lipid nanoparticle. the employment of a lipid mix of solid and liquid forms can deform the production of a 
perfect crystal. The particle-matrix contains imperfections, providing space to accommodate the drug molecules in amorphous clusters (Jores et al., 2005). NLCs are viewed as a more advanced era of nanoparticles, which have enhanced properties for drug loading, adjustment of the delivery profile, and stable medication during storage (Müller et al., 2007). NLCs have many characteristics that are advantageous for dermal application. They can improve the absorption of the incorporated drug into the skin because of their small size that makes close contact with the stratum corneum and the occlusion properties of lipid nanoparticles that increase the skin hydration (Küchler et al., 2010; Liu et al., 2007). In addition, lipid nanoparticles can enhance the chemical stability of compounds sensitive to light, hydrolysis, and oxidation (Jee et al., 2006; Puglia et al., 2006). Therefore, lipid nanoparticles have been used extensively to improve the skin uptake of several drugs (Sanna et al., 2010; Shah et al., 2007). Because of the lipophilic content of the NLCs, they are considered especially helpful in the administration of lipophilic medications.

\section{Types of nanostructured lipid carriers}

There are different types of NLC, That differ according to the composition of lipid mixture and the way of production (Patidar et al., 2010).

- NLCs type I (imperfect crystal type), this type is obtained by mixing a small amount of liquid lipids with solid lipid.

In this type, The matrix of the NLCs is unable to form highly ordered structures resulting in structural imperfections due to the different chain lengths of the various fatty acids and mixture of mono-, di- and triacylglycerols used during their preparations (Müller et al., 2002).

- NLCs type II (amorphous type) in this type, Special lipids that do not recrystallize after homogenization and cooling of nanoemulsion such as hydroxy octacosanyl hydroxy stearate, isopropyl myristate, dibutyl adipate are used.

These lipids form solid particles with an amorphous structure, which decrease the expulsion of the drug, prevent crystallization because the matrix is in the polymorphic $\alpha$ form.
- NLCs type III (multiple types) in this type, solid lipids are mixed with oils, e.g. medium and longchain triacylglycerols (Hu et al., 2006; Souto et al., 2004), oleic acid (Hu et al., 2005) in such a proportion that the solubility of the oil molecules in the solid lipid is passed.

On cooling of the nanoemulsion, the lipid droplets reach the miscibility gap resulting in precipitation of oil, thereby resulting in the formation of tiny oil droplets. Subsequent solidification of the solid lipid surrounding these droplets leads to fixation of the oily nano compartments. Increase in loading capacity for a drug of higher solubility in liquid lipids than in solid lipids is the advantage of this model (Jenning et al., 2000).

\section{Preparation of nanoparticulate structure}

Broadly speaking, energy is normally required in emulsion formulation in light of the fact that the procedure may be non-spontaneous. The creation of nanoemulsions expenses more energy than that required to deliver macroemulsions (Tadros et al., 2004).

The existence of surfactants lowers the surface tensions in the middle of oil and water. During emulsification, an expansion in the interface happens and this makes a lessening in surface excess. The balance is restored by adsorption of surfactant from the bulk, yet this takes additional time (shorter times happen at the higher surfactant activity) (Tadros et al., 2004). In practice, usually we use mixtures of surfactant and these have vigorous effects on surface tension. Some particular surfactant blends give lower surface tension values than both of the two individual segments. Polymersurfactant blends may demonstrate some synergistic

surface activity. An essential part of the emulsifier prohibits shear-induced coalescence during emulsification. The prerequisite is that the continuous- stage has a large surplus of surfactant. This overabundance empowers new surface area of the Nano-scale droplets to be quickly coated during emulsification, thus hindering shear-induced coalescence. This excess is mainly in the form of surfactant micelles in the continuous- stage. These micelles separate into monomers that quickly adsorb onto the surfaces of recently made droplets (Mason et al., 2006). High-energy emulsification routines make utilization of instruments that utilize high mechanical energy to make nanoemulsions with high kinetic energy. The high-energy technique uses mechanical instruments to make serious disruptive 
forces which separate the oil and water stages to make Nano-sized droplets. This can be accomplished with ultrasonicators, microfluidizer and high shear Homogenizers (Graves et al., 2005; Jafari et al., 2007; Mason et al., 2006). Molecule size here will rely on the type of instruments utilized and their working conditions like time and temperature alongside sample properties and compositions (Qian and McClements, 2011). There are different formulation process used to prepare NEs and NLCs such as high-pressure homogenization

\section{References}

Agarwal, A., Saraf, S., Asthana, A., Gupta, U., Gajbhiye, V., Jain, N.K., 2008. Ligand based dendritic systems for tumor targeting. Int. J. Pharm. 350, 3-13.

Alai, M., Lin, W.J., 2015. Application of nanoparticles for oral delivery of acid-labile lansoprazole in the treatment of gastric ulcer: in vitro and in vivo evaluations. International journal of nanomedicine 10, 4029.

Alvarez-Figueroa, M., Blanco-Mendez, J., 2001. Transdermal delivery of methotrexate: iontophoretic delivery from hydrogels and passive delivery from microemulsions. Int. J. Pharm. 215, 57-65.

Barratt, G.M., 2000. Therapeutic applications of colloidal drug carriers. Pharm. Sci. Technolo. Today 3, 163-171.

Behera, A., Sahoo, S.K., 2012. Preparation and evaluation of glibenclamide-loaded biodegradable nanoparticles. Tropical Journal of Pharmaceutical Research 11, 345-350.

Bhadra, S., Prajapati, A.B., Bhadra, D., 2016. Development of $\mathrm{pH}$ sensitive polymeric nanoparticles of erythromycin stearate. J. Pharm. Bioallied Sci. 8, 135.

Bondi', M.L., Azzolina, A., Craparo, E.F., Lampiasi, N., Capuano, G., Giammona, G., Cervello, M., 2007. Novel cationic solid-lipid nanoparticles as non-viral vectors for gene delivery. J. Drug Target. 15, 295-301.

Brannon-Peppas, L., 1995. Recent advances on the use of biodegradable microparticles and nanoparticles in controlled drug delivery. Int. J.
(HUANG, 2008; Ruktanonchai et al., 2009; Štecová et al., 2007), emulsification-sonification (Das and Chaudhury, 2011), double emulsion (Cortesi et al., 2002), melt emulsification (Yuan et al., 2007), microemulsion (Bondi' et al., 2007; Cortesi et al., 2002; Igartua et al., 2002), solvent diffusion (Hu et al., 2002; Trotta et al., 2003), solvent emulsification evaporation (Shahgaldian et al., 2003), probe sonicator (Chen et al., 2010), solvent injection/solvent displacement (Schubert and Müller-Goymann, 2003), phase inversion (Heurtault et al., 2002).

Pharm. 116, 1-9.

Brigger, I., Dubernet, C., Couvreur, P., 2012. Nanoparticles in cancer therapy and diagnosis. Adv. Drug Del. Rev. 64, 24-36.

Chawla, J.S., Amiji, M.M., 2002. Biodegradable poly ( $\varepsilon$-caprolactone) nanoparticles for tumortargeted delivery of tamoxifen. Int. J. Pharm. 249, 127-138.

Chen, C.-C., Tsai, T.-H., Huang, Z.-R., Fang, J.-Y., 2010. Effects of lipophilic emulsifiers on the oral administration of lovastatin from nanostructured lipid carriers: physicochemical characterization and pharmacokinetics. Eur. J. Pharm. Biopharm. 74, 474-482.

Cho, K., Wang, X., Nie, S., Shin, D.M., 2008. Therapeutic nanoparticles for drug delivery in cancer. Clin. Cancer Res. 14, 1310-1316.

Cohen, H., Levy, R., Gao, J., Fishbein, I., Kousaev, V., Sosnowski, S., Slomkowski, S., Golomb, G., 2000. Sustained delivery and expression of DNA encapsulated in polymeric nanoparticles. Gene Ther. 7, 1896.

Cortesi, R., Esposito, E., Luca, G., Nastruzzi, C., 2002. Production of lipospheres as carriers for bioactive compounds. Biomaterials 23, 2283-2294.

Couvreur, P., Dubernet, C., Puisieux, F., 1995. Controlled drug delivery with nanoparticles: current possibilities and future trends. Eur. J. Pharm. Biopharm. 41, 2-13.

Couvreur, P., Vauthier, C., 2006. Nanotechnology: intelligent design to treat complex disease. Pharm. Res. 23, 1417-1450. 
Crommelin, D.J., Storm, G., Jiskoot, W., Stenekes, R., Mastrobattista, E., Hennink, W.E., 2003. Nanotechnological approaches for the delivery of macromolecules. J. Control. Release 87, 81-88.

Damge, C., Michel, C., Aprahamian, M., Couvreur, P., Devissaguet, J., 1990. Nanocapsules as carriers for oral peptide delivery. J. Control. Release 13, 233-239.

Damge, C., Vranckx, H., Balschmidt, P., Couvreur, P., 1997. Poly (alkyl cyanoacrylate) nanospheres for oral administration of insulin. J. Pharm. Sci. 86, 1403-1409.

Das, S., Chaudhury, A., 2011. Recent advances in lipid nanoparticle formulations with solid matrix for oral drug delivery. AAPS PharmSciTech 12, $62-76$

De Jaeghere, F., Allémann, E., Doelker, E., Gurny, R., Cerny, R., Galli, B., Steulet, A., Müller, I., Schütz, H., 2001. pH-dependent dissolving nanoand microparticles for improved peroral delivery of a highly lipophilic compound in dogs. Aaps Pharmsci 3, 92-99.

De Vringer, T., De Ronde, H., 1995. Preparation and structure of a water-in-oil cream containing lipid nanoparticles. J. Pharm. Sci. 84, 466-472.

Desai, M.P., Labhasetwar, V., Amidon, G.L., Levy, R.J., 1996. Gastrointestinal uptake of biodegradable microparticles: effect of particle size. Pharm. Res. 13, 1838-1845.

Desai, M.P., Labhasetwar, V., Walter, E., Levy, R.J., Amidon, G.L., 1997. The mechanism of uptake of biodegradable microparticles in Caco-2 cells is size dependent. Pharm. Res. 14, 1568-1573.

DUGGAL, D., 2011. Role Of Nanotechnology In New Drug Delivery Systems. International Journal of Drug Development and Research 3.

Graves, S., Meleson, K., Wilking, J., Lin, M., Mason, T., 2005. Structure of concentrated nanoemulsions. The Journal of chemical physics 122, 134703.

Gurny, R., Boye, T., Ibrahim, H., 1985. Ocular therapy with nanoparticulate systems for controlled drug delivery. J. Control. Release 2, 353-361.

Heurtault, B., Saulnier, P., Pech, B., Proust, J.-E., Benoit, J.-P., 2002. A novel phase inversion-based process for the preparation of lipid nanocarriers. Pharm. Res. 19, 875-880.
Hu, F.-Q., Jiang, S.-P., Du, Y.-Z., Yuan, H., Ye, Y.Q., Zeng, S., 2005. Preparation and characterization of stearic acid nanostructured lipid carriers by solvent diffusion method in an aqueous system. Colloids Surf. B. Biointerfaces 45, 167-173.

Hu, F.-Q., Jiang, S.-P., Du, Y.-Z., Yuan, H., Ye, Y.Q., Zeng, S., 2006. Preparation and characteristics of monostearin nanostructured lipid carriers. Int. J. Pharm. 314, 83-89.

Hu, F., Yuan, H., Zhang, H., Fang, M., 2002. Preparation of solid lipid nanoparticles with clobetasol propionate by a novel solvent diffusion method in aqueous system and physicochemical characterization. Int. J. Pharm. 239, 121-128.

HUANG, Z.r., 2008. Development and evaluation of lipid nanoparticles for camptothecin delivery: a comparison of solid lipid nanoparticles, nanostructured lipid carriers, and lipid emulsion. Acta Pharmacol. Sin. 29, 1094-1102.

Igartua, M., Saulnier, P., Heurtault, B., Pech, B., Proust, J., Pedraz, J., Benoit, J., 2002. Development and characterization of solid lipid nanoparticles loaded with magnetite. Int. J. Pharm. 233, 149-157.

Jafari, S.M., He, Y., Bhandari, B., 2007. Optimization of nano-emulsions production by microfluidization. Eur. Food Res. Technol. 225, 733-741.

Jee, J.-P., Lim, S.-J., Park, J.-S., Kim, C.-K., 2006. Stabilization of all-trans retinol by loading lipophilic antioxidants in solid lipid nanoparticles. Eur. J. Pharm. Biopharm. 63, 134-139.

Jenning, V., Schäfer-Korting, M., Gohla, S., 2000. Vitamin A-loaded solid lipid nanoparticles for topical use: drug release properties. J. Control. Release 66, 115-126.

Jores, K., Haberland, A., Wartewig, S., Mäder, K., Mehnert, W., 2005. Solid lipid nanoparticles (SLN) and oil-loaded SLN studied by spectrofluorometry and Raman spectroscopy. Pharmaceutical research 22, 1887-1897.

Jung, T., Kamm, W., Breitenbach, A., Kaiserling, E., Xiao, J., Kissel, T., 2000. Biodegradable nanoparticles for oral delivery of peptides: is there a role for polymers to affect mucosal uptake? Eur. J. Pharm. Biopharm. 50, 147-160.

Kadam, R.S., Bourne, D.W., Kompella, U.B., 2012. Nano-advantage in enhanced drug delivery with biodegradable nanoparticles: contribution of 
reduced clearance. Drug Metab. Disposition 40, 1380-1388.

Kaur, I.P., Bhandari, R., Bhandari, S., Kakkar, V., 2008. Potential of solid lipid nanoparticles in brain targeting. J. Control. Release 127, 97-109.

Khopade, A., Jain, N., 1995. Self assembling nanostructures for sustained ophthalmic drug delivery. Die Pharmazie 50, 812-814.

Kreuter, J., 1991. Peroral administration of nanoparticles. Adv. Drug Del. Rev. 7, 71-86.

Küchler, S., Herrmann, W., Panek-Minkin, G., Blaschke, T., Zoschke, C., Kramer, K.D., Bittl, R., Schäfer-Korting, M., 2010. SLN for topical application in skin diseases - Characterization of drug-carrier and carrier-target interactions. Int. J. Pharm. 390, 225-233.

Kumari, A., Yadav, S.K., Yadav, S.C., 2010. Biodegradable polymeric nanoparticles based drug delivery systems. Colloids Surf. B. Biointerfaces 75, 1-18.

Labhasetwar, V., Song, C., Levy, R.J., 1997. Nanoparticle drug delivery system for restenosis. Adv. Drug Del. Rev. 24, 63-85.

Lambert, G., Fattal, E., Couvreur, P., 2001. Nanoparticulate systems for the delivery of antisense oligonucleotides. Adv. Drug Del. Rev. 47, 99-112.

Liu, J., Hu, W., Chen, H., Ni, Q., Xu, H., Yang, $\mathrm{X}$., 2007. Isotretinoin-loaded solid lipid nanoparticles with skin targeting for topical delivery. Int. J. Pharm. 328, 191-195.

Lungu, I.I., Radulescu, M., Mogosanu, G.D., Grumezescu, A.M., 2016. pH sensitive core-shell magnetic nanoparticles for targeted drug delivery in cancer therapy. Rom. J. Morphol. Embryol. 57, 23-32.

Madgulkar, A., Bhalekar, M.R., Dikpati, A.A., 2016. Improving oral bioavailability of acyclovir using nanoparticulates of thiolated xyloglucan. Int. J. Biol. Macromol. 89, 689-699.

Maeda, H., Wu, J., Sawa, T., Matsumura, Y., Hori, K., 2000. Tumor vascular permeability and the EPR effect in macromolecular therapeutics: a review. J. Control. Release 65, 271-284.
Mason, T., Graves, S., Wilking, J., Lin, M., 2006. Extreme emulsification: formation and structure of nanoemulsions. Condensed Matter Physics.

Mishra, R.K., Soni, G., Mishra, R., 2014. A review article: On nanoemulsion. World journal of pharmacy and pharmaceutical sciences, 259.

Moghimi, S.M., Hunter, A.C., Murray, J.C., 2001. Long-circulating and target-specific nanoparticles: theory to practice. Pharmacol. Rev. 53, 283-318.

Moghimi, S.M., Hunter, C., 2001. Capture of stealth nanoparticles by the body's defences. Critical Reviews $^{\text {TM }}$ in Therapeutic Drug Carrier Systems 18.

Mohanraj, V., Chen, Y., 2006. Nanoparticles-a review. Tropical journal of pharmaceutical research 5, 561-573.

MuÈller, R.H., MaÈder, K., Gohla, S., 2000. Solid lipid nanoparticles (SLN) for controlled drug delivery-a review of the state of the art. Eur. J. Pharm. Biopharm. 50, 161-177.

Müller, R., Jacobs, C., Kayser, O., 2001. Nanosuspensions as particulate drug formulations in therapy: rationale for development and what we can expect for the future. Adv. Drug Del. Rev. 47, 3-19.

Müller, R., Petersen, R., Hommoss, A., Pardeike, J., 2007. Nanostructured lipid carriers (NLC) in cosmetic dermal products. Adv. Drug Del. Rev. 59, $522-530$.

Müller, R., Radtke, M., Wissing, S., 2002. Nanostructured lipid matrices for improved microencapsulation of drugs. Int. J. Pharm. 242, 121-128.

Panyam, J., Labhasetwar, V., 2003. Biodegradable nanoparticles for drug and gene delivery to cells and tissue. Adv. Drug Del. Rev. 55, 329-347.

Panyam, J., Labhasetwar, V., 2004. Sustained cytoplasmic delivery of drugs with ntracellular receptors using biodegradable nanoparticles. Mol. Pharm. 1, 77-84.

Panyam, J., Lof, J., O'Leary, E., Labhasetwar, V., 2002a. Efficiency of Dispatch ${ }^{\circledR}$ and Infiltrator ${ }^{\circledR}$ cardiac infusion catheters in arterial localization of nanoparticles in a porcine coronary model of restenosis. J. Drug Target. 10, 515-523.

Panyam, J., Sahoo, S.K., Prabha, S., Bargar, T., Labhasetwar, V., 2003. Fluorescence and electron microscopy probes for cellular and tissue uptake of 
poly (D, L-lactide-co-glycolide) nanoparticles. Int. J. Pharm. 262, 1-11.

Panyam, J., Zhou, W.-Z., Prabha, S., Sahoo, S.K., Labhasetwar, V., 2002b. Rapid endo-lysosomal escape of poly (DL-lactide-co-glycolide) nanoparticles: implications for drug and gene delivery. The FASEB Journal 16, 1217-1226.

Parveen, S., Sahoo, S.K., 2008. Polymeric nanoparticles for cancer therapy. J. Drug Target. $16,108-123$.

Patidar, A., Thakur, D.S., Kumar, P., Verma, J., 2010. A review on novel lipid based nanocarriers. International Journal of Pharmacy and Pharmaceutical Sciences 2, 30-35.

Pignatello, R., Bucolo, C., Ferrara, P., Maltese, A., Puleo, A., Puglisi, G., 2002. Eudragit RS100® nanosuspensions for the ophthalmic controlled delivery of ibuprofen. Eur. J. Pharm. Sci. 16, 5361.

Prabha, S., Labhasetwar, V., 2004. Nanoparticlemediated wild-type p53 gene delivery results in sustained antiproliferative activity in breast cancer cells. Mol. Pharm. 1, 211-219.

Puglia, C., Filosa, R., Peduto, A., De Caprariis, P., Rizza, L., Bonina, F., Blasi, P., 2006. Evaluation of alternative strategies to optimize ketorolac transdermal delivery. AAPS PharmSciTech 7, E61-E69.

Qian, C., McClements, D.J., 2011. Formation of nanoemulsions stabilized by model food-grade emulsifiers using high-pressure homogenization: factors affecting particle size. Food Hydrocolloids $25,1000-1008$.

Ramalingam, P., Ko, Y.T., 2016. Improved oral delivery of resveratrol from $\mathrm{N}$-trimethyl chitosang-palmitic acid surface-modified solid lipid nanoparticles. Colloids Surf. B. Biointerfaces 139, 52-61.

Ruktanonchai, U., Bejrapha, P., Sakulkhu, U., Opanasopit, P., Bunyapraphatsara, N., Junyaprasert, V., Puttipipatkhachorn, S., 2009. Physicochemical characteristics, cytotoxicity, and antioxidant activity of three lipid nanoparticulate formulations of alpha-lipoic acid. AAPS PharmSciTech 10, 227.
Sahoo, S.K., Labhasetwar, V., 2003. Nanotech approaches to drug delivery and imaging. Drug Discov. Today 8, 1112-1120.

Sahoo, S.K., Ma, W., Labhasetwar, V., 2004. Efficacy of transferrin-conjugated paclitaxel-loaded nanoparticles in a murine model of prostate cancer. Int. J. Cancer 112, 335-340.

Sanna, V., Caria, G., Mariani, A., 2010. Effect of lipid nanoparticles containing fatty alcohols having different chain length on the ex vivo skin permeability of Econazole nitrate. Powder Technology 201, 32-36.

Schmidt, C., Bodmeier, R., 1999. Incorporation of polymeric nanoparticles into solid dosage forms. J. Control. Release 57, 115-125.

Schubert, M., Müller-Goymann, C., 2003. Solvent injection as a new approach for manufacturing lipid nanoparticles-evaluation of the method and process parameters. Eur. J. Pharm. Biopharm. 55, 125-131.

Shah, K.A., Date, A.A., Joshi, M.D., Patravale, V.B., 2007. Solid lipid nanoparticles (SLN) of tretinoin: potential in topical delivery. Int. J. Pharm. $345,163-171$.

Shahgaldian, P., Da Silva, E., Coleman, A.W., Rather, B., Zaworotko, M.J., 2003. Para-acyl-calixarene based solid lipid nanoparticles (SLNs): a detailed study of preparation and stability parameters. Int. J. Pharm. 253, 23-38.

Shekunov, B.Y., York, P., 2000. Crystallization processes in pharmaceutical technology and drug delivery design. J. Cryst. Growth 211, 122-136.

Soppimath, K.S., Aminabhavi, T.M., Kulkarni, A.R., Rudzinski, W.E., 2001. Biodegradable polymeric nanoparticles as drug delivery devices. J. Control. Release 70, 1-20.

Štecová, J., Mehnert, W., Blaschke, T., Kleuser, B., Sivaramakrishnan, R., Zouboulis, C.C., Seltmann, H., Korting, H.C., Kramer, K.D., Schäfer-Korting, M., 2007. Cyproterone acetate loading to lipid nanoparticles for topical acne treatment: particle characterisation and skin uptake. Pharm. Res. 24, 991-1000.

Tadros, T., Izquierdo, P., Esquena, J., Solans, C., 2004. Formation and stability of nano-emulsions. Adv. Colloid Interface Sci. 108, 303-318. 
Teeranachaideekul, V., Müller, R.H., Junyaprasert, V.B., 2007. Encapsulation of ascorbyl palmitate in nanostructured lipid carriers (NLC) - effects of formulation parameters on physicochemical stability. Int. J. Pharm. 340, 198206.

Thiagarajan, P., 2011. Nanoemulsions for drug delivery through different routes. Research in Biotechnology 2.

Torchilin, V.P., 2012. Multifunctional nanocarriers. Adv. Drug Del. Rev. 64, 302-315.

Trotta, M., Debernardi, F., Caputo, O., 2003. Preparation of solid lipid nanoparticles by a solvent emulsification-diffusion technique. Int. J. Pharm. 257, 153-160.

Vauthier, C., Dubernet, C., Fattal, E., PintoAlphandary, H., Couvreur, P., 2003. Poly (alkylcyanoacrylates) as biodegradable materials for biomedical applications. Adv. Drug Del. Rev. 55, 519-548.

Yang, L., Alexandridis, P., 2000. Physicochemical aspects of drug delivery and release from polymerbased colloids. Current Opinion in Colloid \& Interface Science 5, 132-143.

Yang, Y.Y., Wang, Y., Powell, R., Chan, P., 2006. POLYMERIC CORE-SHELL NANOPARTICLES FOR THERAPEUTICS. Clin. Exp. Pharmacol. Physiol. 33, 557-562.

Yuan, H., Wang, L.-L., Du, Y.-Z., You, J., Hu, F.Q., Zeng, S., 2007. Preparation and characteristics of nanostructured lipid carriers for control-releasing progesterone by melt-emulsification. Colloids Surf. B. Biointerfaces 60, 174-179. 